\title{
Postoperative adjuvant chemotherapy versus chemoradiotherapy for node- positive esophageal squamous cell carcinoma: a propensity score-matched analysis
}

Qifeng Wang ${ }^{1,2+}$, Jinyi Lang ${ }^{1 \dagger}$, Tao $\mathrm{Li}^{1}$, Lin Peng ${ }^{3 *}$, Wei Dai ${ }^{3}$, Yinchun Jiang ${ }^{3}$, Tianpeng Xie ${ }^{3}$, Qiang Fang ${ }^{3}$, Yi Wang ${ }^{1,2}$, Lei $\mathrm{Wu}^{1,2}$, Bangrong $\mathrm{CaO}^{2}$ and Yongtao $\mathrm{Han}^{3^{*}}$

\begin{abstract}
Background and purpose: After esophagectomy, adjuvant chemotherapy $(\mathrm{S}+\mathrm{CT})$ and adjuvant chemoradiotherapy $(S+C R T)$ can improve survival in patients with node-positive resectable esophageal cancer. However, we are not aware of any studies that directly compared these adjuvant treatments. This study aimed to compare $\mathrm{S}+\mathrm{CT}$ and $\mathrm{S}+\mathrm{CRT}$ for patients with esophageal cancer.
\end{abstract}

Materials and methods: We retrospectively identified patients with node-positive esophageal squamous cell carcinoma who underwent S + CT or S + CRT at Sichuan Cancer Hospital during 2008-2017. The patients' characteristics were compared, as well as their overall survival (OS) and disease-free survival (DFS) outcomes. Propensity score matching was used to create balanced patient groups according to adjuvant treatment, and a Cox proportional hazards model was used to identify factors that predicted the survival outcomes.

Results: The 859 eligible patients underwent S + CRT (250 patients, 29.1\%) or S + CT (609 patients, 70.9\%). After propensity score matching (247 patients per group), the 5 -year OS rates were $41.8 \%$ for $S+C R T$ and $26.8 \%$ for $S+$ $C T(p=0.028)$, and the 5 -year DFS rates were $37.2 \%$ for $S+C R T$ and $25.5 \%$ for $S+C T(p=0.012)$. Multivariate Cox regression analysis of the matched samples revealed that, relative to the $S+C T$ group, the $S+C R T$ group had better OS (hazard ratio: $0.71,95 \%$ Cl: $0.56-0.91 ; p=0.006$ ) and DFS (hazard ratio: $0.70,95 \%$ Cl: $0.56-0.88 ; p=0.002$ ).

Conclusion: Among patients with node-positive resectable esophageal squamous cell carcinoma, $S+C R T$ was associated with better OS than $S+C T$. A multicenter randomized clinical trial is warranted to confirm these findings.

Keywords: Adjuvant therapy, Esophagectomy, Esophageal cancer, Chemotherapy, Chemoradiotherapy

\footnotetext{
*Correspondence: penglinms@126.com; hanyongt2019@163.com

${ }^{\dagger}$ Qifeng Wang and Jinyi Lang contributed equally to this work.

${ }^{3}$ Department of Thoracic Surgery, Sichuan Cancer Hospital \& Institution,

Sichuan Cancer Center, School of Medicine, University of Electronic Science

and Technology of China, Radiation Oncology Key Laboratory of Sichuan

Province, Chengdu 610041, China

Full list of author information is available at the end of the article
}

(c) The Author(s). 2020 Open Access This article is licensed under a Creative Commons Attribution 4.0 International License, which permits use, sharing, adaptation, distribution and reproduction in any medium or format, as long as you give appropriate credit to the original author(s) and the source, provide a link to the Creative Commons licence, and indicate if changes were made. The images or other third party material in this article are included in the article's Creative Commons licence, unless indicated otherwise in a credit line to the material. If material is not included in the article's Creative Commons licence and your intended use is not permitted by statutory regulation or exceeds the permitted use, you will need to obtain permission directly from the copyright holder. To view a copy of this licence, visit http://creativecommons.org/licenses/by/4.0/ The Creative Commons Public Domain Dedication waiver (http://creativecommons.org/publicdomain/zero/1.0/) applies to the data made available in this article, unless otherwise stated in a credit line to the data. 


\section{Introduction}

Esophageal cancer is associated with a poor prognosis and substantial mortality rate $[1,2]$. Although esophagectomy is the main treatment option for patients with localized advanced esophageal cancer, the 5-year overall survival (OS) rate remains $<20 \%$ after surgery alone [3-7]. Furthermore, patients with pathologic lymph node LN metastasis have a significantly lower survival rate than patients without LN metastasis $[4,5,8,9]$. Several studies have indicated that, relative to surgery alone, multimodality treatment significantly improves OS among patients with locally advanced esophageal cancer [5, 8, 10-13]. The main additional treatment for locally advanced esophageal squamous cell carcinoma and adenocarcinoma is neoadjuvant chemoradiotherapy (NCRT), based on the results from the CROSS study [11] and the NEOCRTEC5010 study [10]. Recently some researchers reported persistent pathologic LN metastasis with or without NCRT is a strong poor prognostic factor in ESCC $[14,15]$. Therefore, an effective preoperative or postoperative treatment (e.g., radiotherapy and/or chemotherapy) is needed to improve outcomes, especially for patients with pathologically nodepositive $(\mathrm{pN}+)$ esophageal cancer. Postoperative chemotherapy and/or radiotherapy provide significantly better long-term survival, relative to surgery alone, for patients with $\mathrm{pN}+$ esophageal cancer $[3,5,7,13]$. However, to the best of our knowledge, no studies have directly compared $\mathrm{S}+\mathrm{CT}$ and $\mathrm{S}+\mathrm{CRT}$ for $\mathrm{pN}+$ esophageal squamous cell carcinoma (ESCC). Therefore, this retrospective study examined whether $\mathrm{S}+\mathrm{CT}$ or $\mathrm{S}+\mathrm{CRT}$ were associated with improved survival among patients with $\mathrm{pN}+\mathrm{ESCC}$.

\section{Patients and methods}

\section{Patient selection}

Between January 2008 and December 2017, we retrospectively identified 1034 patients who underwent esophagectomy with curative intent (Fig 1). The eligibility criteria were: (1) histologically proven thoracic ESCC; (2) R0 and R1-2 resection; (3) standard McKeown esophagectomy or Ivor-Lewis esophagectomy; (4) pathological classification of any size tumor (T1-T4), regional lymph node metastasis (N1-3), and no distant metastases (pathological stage IIb, III, or IVa); (5) age of $\geq 18$ years and Karnofsky performance status (KPS) of $\geq 80$; (6) adequate bone marrow, renal, and hepatic functions; and (7) underwent postoperative chemotherapy or chemoradiotherapy. The exclusion criteria were cervical esophageal tumors, adenocarcinoma, and small cell carcinoma. The study's retrospective protocol was approved by the appropriate institutional review board.

\section{Surgery}

All patients received intravenous and inhalation-based general anesthesia. The surgical techniques were standard McKeown esophagectomy $(n=343)$ or IvorLewis esophagectomy $(n=516)$. The surgical approaches were minimally invasive esophagectomy $(n=319)$ and open esophagectomy $(n=540)$. The surgical specimen was retrospectively restaged based on the 8th edition of the TNM classification for esophageal cancer [5].

\section{Chemotherapy}

The S + CT group included 609 patients and the S+ CRT group included 250 patients. Cisplatin-based regimens were used for 196 patients in the $\mathrm{S}+\mathrm{CT}$ group and 124 patients in the $\mathrm{S}+\mathrm{CRT}$ group. Nedaplatinbased regimens were used for 239 patients in the $\mathrm{S}+\mathrm{CT}$ group and 32 patients in the $\mathrm{S}+\mathrm{CRT}$ group. Oxaliplatin-based regimens were used for 131 patients in the $\mathrm{S}+\mathrm{CT}$ group and 50 patients in the $\mathrm{S}+\mathrm{CRT}$ group. Carboplatin-based regimens were used for 13 patients in the $\mathrm{S}+\mathrm{CT}$ group and 1 patient in the $\mathrm{S}+\mathrm{CRT}$ group. In addition, Gimeracil and Oteracil Porassium Capsules (S1) treatment was provided for 30 patients in the $S+C T$ group and 43 patients in the $S+$ CRT group. In the $\mathrm{S}+\mathrm{CRT}$ group, 116 patients received concurrent chemoradiation with sequential chemotherapy and 134 patients received concurrent chemoradiation without sequential chemotherapy.

\section{Radiotherapy}

Radiotherapy was started at 4-10 weeks after surgery. Computed tomography was used to identify anatomical landmarks and delineate the mediastinal lymph node stations. The clinical target volume was defined as both the tumor bed and high-risk lymphatic drainage areas. Postoperative radiotherapy was avoided for patients with a gastric tube located at the primary esophageal bed. Any anastomosis was included in the clinical target volume for patients with upper thoracic tumors and patients who had an insufficient proximal margin $(<3 \mathrm{~cm})$. The radiotherapy involved a total dose of 50-54 Gy delivered to $95 \%$ of the planning target volume in $25-30$ fractions (5 fractions/week for 5-6 weeks).

\section{Outcomes}

All patients were followed every 3-6 months for the first 2 years after treatment, every 6-12 months for the following 3 years, and then annually thereafter. The follow-up evaluations included computed tomography scans of the neck, chest, and upper abdomen; ultrasonographic examination of the neck and upper abdomen; nuclear bone scanning; and blood routine test and biochemical tests. Esophagogastroscopy, positron emission tomographycomputed tomography, and fine-needle aspiration cytology were performed when necessary. Recurrence was defined as locoregional recurrence (LRR, recurrence in the supraclavicular, mediastinal, and peritoneal regions) or 
distant metastasis (any other form of recurrence), and the relapse was confirmed via computed tomography, magnetic resonance imaging, or endoscopic examination of the corresponding site. Cytology or histology was performed if necessary. Multiple relapses detected within 1 month were considered synchronous.

The OS interval was calculated from the date of surgery until the date of death or the last follow-up, with surviving patients being censored at the last date of contact. The disease-free survival (DFS) interval was the length of time after primary treatment for a cancer ends that the patient survives without any signs or symptoms, with surviving patients being censored at the last date without any evidence of relapse.

\section{Statistical analysis}

The groups' OS and DFS values were compared using the Kaplan-Meier method and the unstratified log-rank test. A Cox regression model with stepwise selection was used for the multivariate analyses, and the results were reported as hazard ratios (HRs) with 95\% confidence intervals (CIs). To further adjust for unbalanced covariates, we performed propensity score matching to create two comparable groups of patients who underwent surgery plus adjuvant chemotherapy (the $\mathrm{S}+\mathrm{CT}$ group) or surgery plus adjuvant chemoradiotherapy (the $\mathrm{S}+\mathrm{CRT}$ group). The patients' propensity scores were estimated using a logit model that included age, sex, KPS, weight loss, tumor length, tumor location, pathological grade, lymphovascular invasion, nerve invasion, number of resected nodes, and TNM stage. Nearest neighbor matching (1:1) was performed without replacement based on a prespecified caliper width to match patients in the $\mathrm{S}+\mathrm{CT}$ and $\mathrm{S}+\mathrm{CRT}$ groups. Differences were considered statistically significant at $p$-values of $<0.05$.

\section{Results}

\section{Patient characteristics}

Between January 2008 and December 2017, we retrospectively identified 1787 consecutive patients with $\mathrm{pN}+$ ESCC. Based on the inclusion and exclusion criteria, we included 859 patients who underwent either S + CT (609 patients) or S + CRT (250 patients). The patients' clinical characteristics are shown in Table 1. The two groups had similar clinical and pathological characteristics (e.g., age, sex, tumor status, histology differentiation, vascular invasion, nerve invasion, and node dissection). However, relative to the $\mathrm{S}+\mathrm{CT}$ group, the $\mathrm{S}+\mathrm{CRT}$ group had significant better performance status $(p=0.001)$, more upper site locations $(p<0.001)$, more $\mathrm{R} 1-2$ margins $(p=$ $0.002)$, and more two-field lymph node dissections $(p<$ $0.001)$. The $\mathrm{S}+\mathrm{CT}$ group was more likely to have pT3 status than the $\mathrm{S}+\mathrm{CRT}$ group $(p=0.021)$. After the propensity score matching, the two matched groups had similar clinical and pathological characteristics (Table 1).

\section{Survival}

The median follow-up for all patients was 42.5 months (range: 3-116 months), with a 3-year OS rate of $46.2 \%$ and a 5-year OS rate of $31.7 \%$ (median OS: 31.7 months). The 3-year DFS rate was $37.0 \%$ and the 5-year DFS rate was $28.1 \%$ (median DFS: 21.9 months). Relative to the S + CT group (3-year OS: 43.5\%, 5-year OS: $27.0 \%$, median OS: 30.4 months), the $\mathrm{S}+\mathrm{CRT}$ group had significantly better OS outcomes (3-year OS: 52.2\%, 5-year OS: 42.0\%, median OS: 39.3 months; $p=0.006$ ) (Fig. 2a). Relative to the S + CT group (3-year DFS: 33.4\%, 5-year DFS: $24.3 \%$, median DFS: 21 months), the $\mathrm{S}+\mathrm{CRT}$ group had significantly longer DFS outcomes (3-year DFS: 44.9\%, 5-year DFS: 37.1\%, median DFS: 26.2 months; $p=$ 0.004) (Fig. 2b).

\section{Outcomes in the matched groups}

When we considered the propensity score-matched groups, the S + CT group had poorer OS outcomes (3year OS: 45.3\%, 5-year OS: 26.8\%, median OS: 32.1 months) than the S + CRT group (3-year OS: $52.0 \%$, 5year OS: $41.8 \%$, median OS: 39.3 months; $p=0.023$ ) (Fig. 3a). In addition, the $\mathrm{S}+\mathrm{CT}$ group had poorer DFS outcomes (3-year DFS: 33.3\%, 5-year DFS: 25.5\%, median DFS: 2.1 months) than the $\mathrm{S}+\mathrm{CRT}$ group (3-year DFS: 45.1\%, 5-year DFS: 37.1\%, median DFS: 26.2 months; $p=0.012$ ) (Fig. 3b).

\section{Univariate and multivariate analyses of the matched groups}

Univariate analyses revealed that the survival outcomes were associated with the KPS score, surgical technique, surgical margin, vascular invasion, nerve invasion, and postoperative pathological $\mathrm{T} / \mathrm{N}$ status (Supplementary Table 1). When we considered the propensity scorematched groups, the multivariate Cox regression analyses confirmed that $\mathrm{S}+\mathrm{CRT}$ was independently associated with better OS, relative to S + CT (HR: 0.71, 95\% CI: $0.56-0.91 ; p=0.006$ ) (Table 2). In addition, OS was independently predicted by KPS score, number of dissected nodes, surgical margin, vascular invasion, and pathological $\mathrm{T} / \mathrm{N}$ status. Furthermore, in the propensity score-matched groups, S + CRT was associated with better DFS, relative to S + CT (HR: 0.70, 95\% CI: 0.56-0.88; $p=0.002)$. The other independent predictors of DFS were KPS score and pathological T/N status.

\section{Subgroup analyses in the matched groups}

For patients with KPS scores of 90-100, the S + CRT group had similar 5-year rates of OS and DFS, relative to the $\mathrm{S}+\mathrm{CT}$ group. For patient with KPS scores of 70- 
Table 1 Clinicopathological characteristics of the patients before and after propensity score matching

\begin{tabular}{|c|c|c|c|c|c|c|c|c|}
\hline & & Before PSM & & & & After PSM & & \\
\hline & All $\boldsymbol{n}=859$ & $\begin{array}{l}S+C T \\
\boldsymbol{n}=609(\%)\end{array}$ & $\begin{array}{l}S+C R T \\
\boldsymbol{n}=250(\%)\end{array}$ & P-value & All $\boldsymbol{n}=494$ & $S+C T \boldsymbol{n}=247(\%)$ & $\begin{array}{l}\mathrm{S}+\mathrm{CRT} \\
\mathrm{n}=247(\%)\end{array}$ & P-value \\
\hline Age, years & & & & 0.301 & & & & 1.000 \\
\hline$\leq 65$ & $674(78.46)$ & $484(79.5)$ & $190(76)$ & & $377(76.32)$ & $189(76.5)$ & 188(76.1) & \\
\hline$>65$ & $185(21.54)$ & $125(20.5)$ & $60(24)$ & & $117(23.68)$ & $58(23.5)$ & $59(23.9)$ & \\
\hline Sex & & & & 0.580 & & & & 0.215 \\
\hline Male & 735(85.56) & $518(85.1)$ & $217(86.8)$ & & $417(84.41)$ & $203(82.2)$ & $214(86.6)$ & \\
\hline Female & $124(14.44)$ & 91(14.9) & $33(13.2)$ & & $77(15.59)$ & $44(17.8)$ & $33(13.4)$ & \\
\hline KPS score & & & & 0.001 & & & & 0.786 \\
\hline $90-100$ & $399(46.45)$ & $260(42.7)$ & $139(55.6)$ & & $278(56.28)$ & $141(57.1)$ & $137(55.5)$ & \\
\hline $70-80$ & $460(53.55)$ & $349(57.3)$ & $111(44.4)$ & & 216(43.72) & $106(42.9)$ & $110(44.5)$ & \\
\hline Surgery type & & & & 0.010 & & & & 0.279 \\
\hline Open & $540(62.86)$ & $400(65.7)$ & $140(56)$ & & $265(53.64)$ & $126(51)$ & $139(56.3)$ & \\
\hline MIE & $319(37.14)$ & $209(34.3)$ & $110(44)$ & & $229(46.36)$ & $121(49)$ & $108(43.7)$ & \\
\hline lymph node dissection & & & & $<0.001$ & & & & 0.917 \\
\hline two fields & $516(60.07)$ & $326(53.5)$ & $190(76)$ & & $372(75.3)$ & $185(74.9)$ & $187(75.7)$ & \\
\hline three fields & $343(39.93)$ & $283(46.5)$ & $60(24)$ & & $122(24.7)$ & $62(25.1)$ & $60(24.3)$ & \\
\hline Pathological differentiation & & & & 0.305 & & & & 0.671 \\
\hline Well (G1) & $111(12.92)$ & $76(12.5)$ & $35(14)$ & & $73(14.78)$ & $39(15.8)$ & $34(13.8)$ & \\
\hline Moderate (G2) & $366(42.61)$ & $252(41.4)$ & $114(45.6)$ & & 215(43.52) & $103(41.7)$ & $112(45.3)$ & \\
\hline Poor or undifferentiated (G3-4) & $382(44.47)$ & $281(46.1)$ & $101(40.4)$ & & 206(41.7) & $105(42.5)$ & $101(40.9)$ & \\
\hline Location & & & & $<0.001$ & & & & 0.449 \\
\hline Upper site & $166(19.32)$ & $92(15.1)$ & $74(29.6)$ & & $134(27.13)$ & $62(25.1)$ & $72(29.1)$ & \\
\hline Middle site & $456(53.08)$ & $323(53)$ & $133(53.2)$ & & 265(53.64) & $133(53.8)$ & $132(53.4)$ & \\
\hline Lower site & $237(27.59)$ & 194(31.9) & $43(17.2)$ & & $95(19.23)$ & $52(21.1)$ & $43(17.4)$ & \\
\hline Resection & & & & 0.002 & & & & 0.430 \\
\hline Ro & $803(93.48)$ & $580(95.2)$ & $223(89.2)$ & & $450(91.09)$ & $228(92.3)$ & $222(89.9)$ & \\
\hline R1-2 & $56(6.52)$ & $29(4.8)$ & $27(10.8)$ & & $44(8.91)$ & 19(7.7) & $25(10.1)$ & \\
\hline Varscular Invasion & & & & 0.210 & & & & 0.397 \\
\hline Yes & $647(75.32)$ & $451(74.1)$ & $196(78.4)$ & & $377(76.32)$ & $184(74.5)$ & 193(78.1) & \\
\hline No & $212(24.68)$ & $158(25.9)$ & $54(21.6)$ & & $117(23.68)$ & $63(25.5)$ & $54(21.9)$ & \\
\hline Nerve invasion & & & & 1.000 & & & & 0.391 \\
\hline Yes & $677(78.81)$ & $480(78.8)$ & $197(78.8)$ & & $381(77.13)$ & $186(75.3)$ & 195(78.9) & \\
\hline No & $182(21.19)$ & $129(21.2)$ & $53(21.2)$ & & $113(22.87)$ & $61(24.7)$ & $52(21.1)$ & \\
\hline Dissection nodes & & & & 0.394 & & & & 0.652 \\
\hline$\leq \mathbf{2 0}$ & $406(47.26)$ & 294(48.3) & $112(44.8)$ & & $226(45.75)$ & $116(47)$ & $110(44.5)$ & \\
\hline$>20$ & $453(52.74)$ & $315(51.7)$ & $138(55.2)$ & & $268(54.25)$ & $131(53)$ & $137(55.5)$ & \\
\hline Pathological T status & & & & $<0.001$ & & & & 0.130 \\
\hline T1 & $42(4.89)$ & $30(4.9)$ & $12(4.8)$ & & $18(3.64)$ & $6(2.4)$ & $12(4.9)$ & \\
\hline T2 & $148(17.23)$ & $110(18.1)$ & $38(15.2)$ & & $74(14.98)$ & $36(14.6)$ & $38(15.4)$ & \\
\hline T3 & $573(66.71)$ & $419(68.8)$ & 154(61.6) & & $329(66.6)$ & $175(70.9)$ & $154(62.3)$ & \\
\hline T4a & $87(10.13)$ & $49(8)$ & $38(15.2)$ & & $67(13.56)$ & $29(11.7)$ & $38(15.4)$ & \\
\hline T4b & $9(1.05)$ & $1(0.2)$ & $8(3.2)$ & & $6(1.21)$ & $1(0.4)$ & $5(2)$ & \\
\hline Pathological N status & & & & 0.057 & & & & 0.327 \\
\hline
\end{tabular}


Table 1 Clinicopathological characteristics of the patients before and after propensity score matching (Continued)

\begin{tabular}{|c|c|c|c|c|c|c|c|c|}
\hline & \multirow[b]{2}{*}{ All $\boldsymbol{n}=859$} & \multicolumn{2}{|l|}{ Before PSM } & \multirow[b]{2}{*}{ P-value } & \multirow[b]{2}{*}{ All $\boldsymbol{n}=494$} & \multicolumn{2}{|l|}{ After PSM } & \multirow[b]{2}{*}{ P-value } \\
\hline & & $\begin{array}{l}S+C T \\
\boldsymbol{n}=609(\%)\end{array}$ & $\begin{array}{l}S+C R T \\
\boldsymbol{n}=250(\%)\end{array}$ & & & $S+C T \boldsymbol{n}=247(\%)$ & $\begin{array}{l}\mathrm{S}+\mathrm{CRT} \\
\mathrm{n}=247(\%)\end{array}$ & \\
\hline N1 & $455(52.97)$ & $320(52.5)$ & $135(54)$ & & $281(56.88)$ & $148(59.9)$ & 133(53.8) & \\
\hline N2 & $270(31.43)$ & $183(30)$ & $87(34.8)$ & & $157(31.78)$ & $71(28.7)$ & $86(34.8)$ & \\
\hline N3 & $134(15.6)$ & $106(17.4)$ & $28(11.2)$ & & $56(11.34)$ & $28(11.3)$ & $28(11.3)$ & \\
\hline Pathological TNM stage & & & & 0.896 & & & & 0.629 \\
\hline IIB & $28(3.26)$ & $20(3.3)$ & $8(3.2)$ & & $13(2.63)$ & $5(2)$ & $8(3.2)$ & \\
\hline IIIA & $97(11.29)$ & $72(11.8)$ & $25(10)$ & & $52(10.53)$ & $27(10.9)$ & $25(10.1)$ & \\
\hline IIIB & $562(65.42)$ & $396(65)$ & $166(66.4)$ & & $341(69.03)$ & $175(70.9)$ & $166(67.2)$ & \\
\hline IVA & $172(20.02)$ & $121(19.9)$ & $51(20.4)$ & & $88(17.81)$ & $40(16.2)$ & $48(19.4)$ & \\
\hline
\end{tabular}

Note: AJCC American Joint Committee on Cancer, $S$ Surgery alone, $S+C T$ Postoperative chemotherapy, $S+C R T$ postoperative chemoradiotherapy, OS Overall survival, DFS Disease-free survival, HR Hazard ratio, Cl Confident interval, KPS Karnofsky Performance Status, MIE Minimally invasive esophagectomy

80 , the $\mathrm{S}+\mathrm{CRT}$ group had significantly better 5 -year rates of OS $(39.1 \%$ vs. $17.8 \%, p=0.011)$ and DFS $(31.9 \%$ vs. $13.7 \%, p=0.038$ ) (Supporting Figure 1). For patients with pT1-2 status, the $\mathrm{S}+\mathrm{CRT}$ group had similar 5-year rates of OS and DFS, relative to the $\mathrm{S}+\mathrm{CT}$ group. For patients with pT3-4 status, the S + CRT group had significantly better 5 -year rates of OS (39.6\% vs. $23.9 \%, p=$ $0.043)$ and DFS (35.2\% vs. $23.2 \%, p=0.016)$ (Supporting Figure 2D). For patients with pN2-3 status, the $\mathrm{S}+\mathrm{CRT}$ group had similar 5-year rates of OS and DFS, relative to the $\mathrm{S}+\mathrm{CT}$ group. For patient with $\mathrm{pN} 1$ status, the $\mathrm{S}+\mathrm{CRT}$ group had significantly better 5 -year rates of

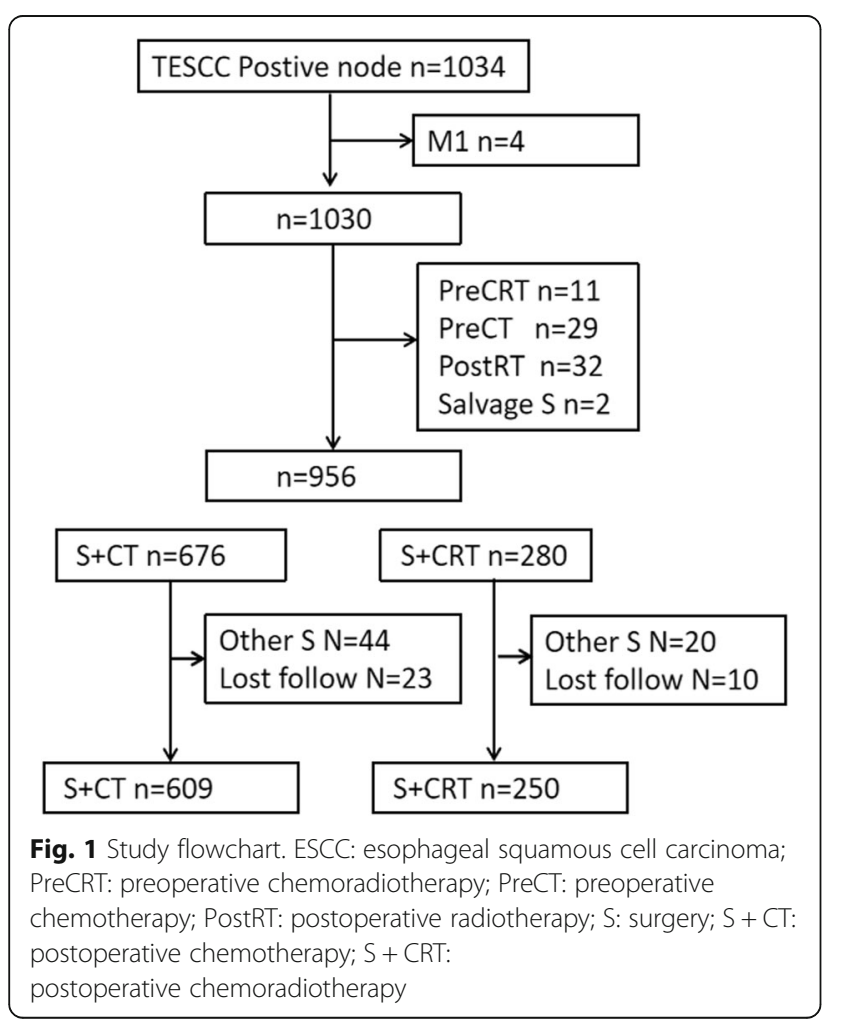

OS $(57.3 \%$ vs. $36.4 \%, p=0.007)$ and DFS $(52.1 \%$ vs. $36.5 \%, p=0.007$ ) (Supporting Figure 3).

\section{Patterns of failure in the matched groups}

Based on the findings at the last follow-up, the localregional recurrence rate was significantly lower in the $\mathrm{S}+$ CRT group than in the S + CT group (27.1\% [67/247] vs. $34.8 \%$ [86/247], $p=0.023)$. In the $\mathrm{S}+\mathrm{CRT}$ group, the recurrences involved the mediastinal lymph nodes $(16.2 \%,[40 / 247])$, the supraclavicular lymph nodes $(8.1 \%$, [20/247]), and the abdominal lymph nodes (1.6\%,[4/ 247]), with 7 cases $(2.8 \%,[7 / 247])$ involving anastomotic recurrence (1 case related to an esophageal fistula). In the $\mathrm{S}+\mathrm{CT}$ group, the recurrences involved the mediastinal lymph nodes $(22.7 \%,[56 / 247])$, the supraclavicular lymph nodes $(6.5 \%,[16 / 247])$, and the abdominal lymph nodes $(4.9 \%,[12 / 247])$, with 2 cases involving anastomotic recurrence $(0.8 \%,[2 / 247])$. The two groups had similar rates of distant metastasis (S + CRT: 45/247 [18.2\%], S + CT: 47/247 [19.0\%]; $p=0.779)$, which commonly involved the lungs $(n=37,[20 / 247])$, liver $(n=25$, [20/247]), bones $(n=21,[20 / 247])$ and other organs $(n=$ 9).

\section{Discussion}

The current National Comprehensive Cancer Network guidelines [17] recommend no additional treatment for squamous esophageal cancer unless the surgical margins are positive, although even patients with complete resection have a poor prognosis. The present study evaluated patients with pN+ ESCC and found that S + CRT was associated with a survival advantage in terms of OS and DFS, relative to $\mathrm{S}+\mathrm{CT}$. Furthermore, this advantage was still observed when we compared the propensity scorematched groups. Moreover, the independent predictors of OS and DFS were S + CRT, KPS score, and pathological T/N status. Finally, $\mathrm{S}+\mathrm{CRT}$ was associated with a significantly lower LRR (relative to $\mathrm{S}+\mathrm{CT}$ ), although 

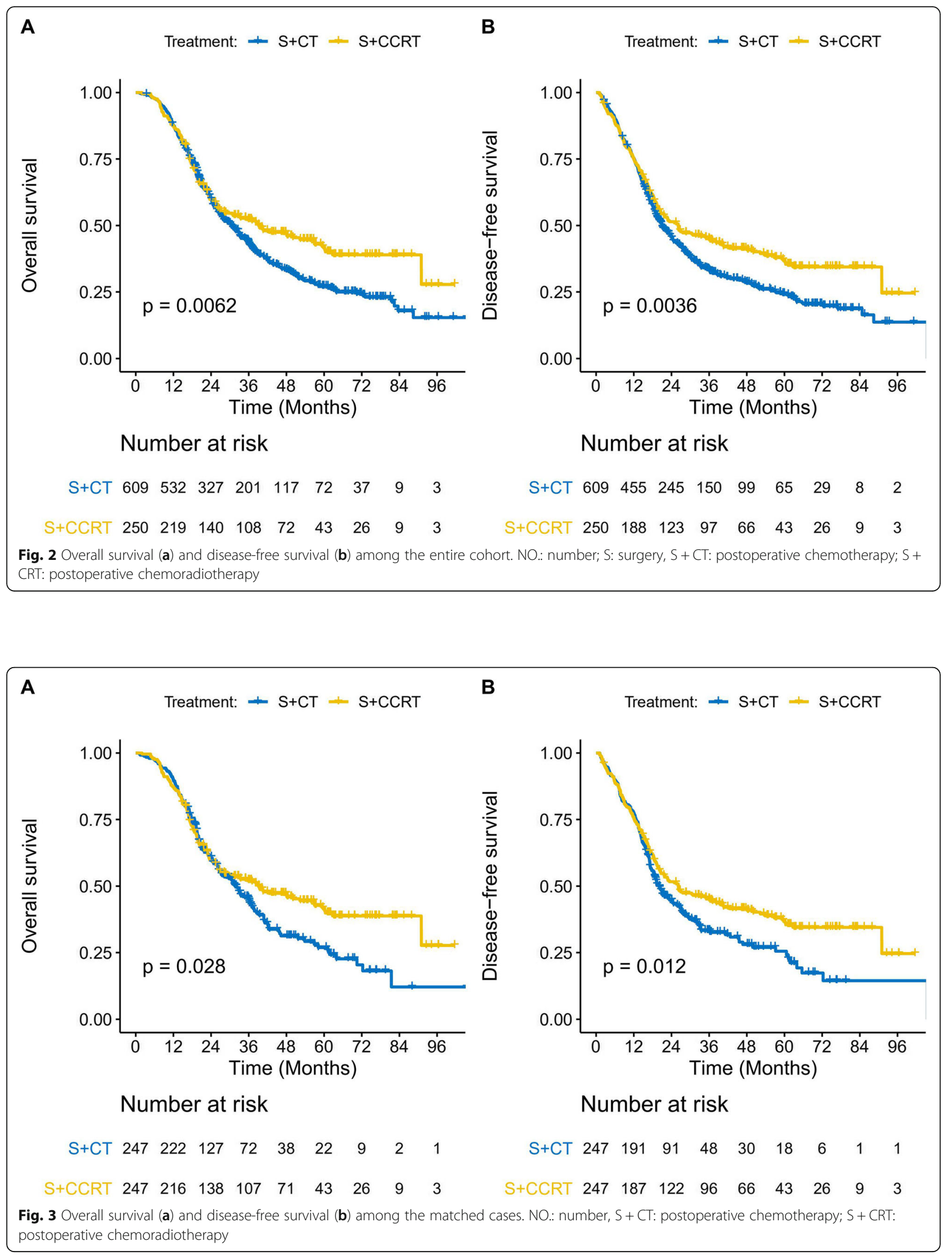
Table 2 Multivariate analysis of factors influencing overall survival and disease-free survival in the matched groups(Multivariate Cox regression for both $P<0.1$ for OS and DFS in Univariate analysis)

\begin{tabular}{|c|c|c|c|c|c|}
\hline & & \multicolumn{2}{|l|}{ Overall survival } & \multicolumn{2}{|c|}{ Disease free survival } \\
\hline & & $\mathrm{HR}(95 \% \mathrm{Cl})$ & $\boldsymbol{P}$ value & $\mathrm{HR}(95 \% \mathrm{Cl})$ & $\boldsymbol{P}$ value \\
\hline \multirow[t]{2}{*}{ KPS } & $90-100$ & 1 & & 1 & \\
\hline & $70-80$ & $1.35(1.06-1.71)$ & 0.014 & $1.3(1.03-1.63)$ & 0.025 \\
\hline \multirow[t]{2}{*}{ Operation type } & Open & 1 & & 1 & \\
\hline & $\operatorname{mini}$ & $0.86(0.67-1.11)$ & 0.255 & $0.8(0.63-1.02)$ & 0.070 \\
\hline \multirow[t]{2}{*}{ Margin } & Ro & 1 & & 1 & \\
\hline & R1-2 & $1.53(1.05-2.22)$ & 0.028 & $1.22(0.84-1.79)$ & 0.294 \\
\hline \multirow[t]{2}{*}{ Varscular Invasion } & No & 1 & & 1 & \\
\hline & Yes & $1.34(1.02-1.78)$ & 0.037 & $1.18(0.91-1.54)$ & 0.220 \\
\hline \multirow[t]{2}{*}{ Neuro Invasion } & No & 1 & & 1 & \\
\hline & Yes & $1.02(0.76-1.36)$ & 0.903 & $1.22(0.93-1.61)$ & 0.153 \\
\hline \multirow[t]{5}{*}{ Path T stage } & $\mathrm{T} 1$ & 1 & & 1 & \\
\hline & $\mathrm{T} 2$ & $2.22(0.78-6.31)$ & 0.134 & $1.48(0.66-3.33)$ & 0.347 \\
\hline & T3 & $2.53(0.93-6.86)$ & 0.069 & $1.66(0.78-3.56)$ & 0.192 \\
\hline & T4a & $3.79(1.34-10.71)$ & 0.012 & $2.19(0.97-4.93)$ & 0.059 \\
\hline & T4b & $22.24(6.04-81.86)$ & 0.000 & $8.12(2.61-25.3)$ & 0.000 \\
\hline \multirow[t]{3}{*}{ Path N stage } & N1 & & & & \\
\hline & N2 & $2.05(1.58-2.65)$ & 0.000 & $1.85(1.44-2.37)$ & 0.000 \\
\hline & N3 & $2.65(1.86-3.76)$ & 0.000 & $2.45(1.74-3.45)$ & 0.000 \\
\hline \multirow[t]{2}{*}{ Adjuvant Therapy } & $\mathrm{S}+\mathrm{CT}$ & & & & \\
\hline & $\mathrm{S}+\mathrm{CRT}$ & $0.71(0.56-0.91)$ & 0.006 & $0.7(0.56-0.88)$ & 0.002 \\
\hline
\end{tabular}

$\mathrm{S}+\mathrm{CRT}$ did not appear to affect the rate of distant metastasis.

Surgical techniques for esophageal cancer have improved dramatically over the last decade, from two-field dissection to three-field dissection and from open surgery to video-assisted thoracoscopic minimally invasive surgery [16-18]. These advances have led to improvements in survival. However, local recurrence remains the main cause of treatment failure among patients with locally advanced tumors (41.5-49\% of cases) [17, 19, 20]. A few studies reported that additional preoperative and postoperative therapy is necessary for patients with $\mathrm{pN}+$ disease $[3,4,8,22-24]$. Hsu et al. also reported that, among $\mathrm{pN}+$ patients, $\mathrm{S}+\mathrm{CRT}$ provided better outcomes than surgery alone in terms of 3 -year OS $(45.8 \%$ vs. $14.1 \%, p<0.001)$ and 3 -year DFS $(24.1 \%$ vs. $11.5 \%, p=$ 0.0002) [25]. Furthermore, Lee et al. reported that $S+$ $\mathrm{CT}$ was associated with a significantly better 3-year DFS rate than surgery alone $(47.6 \%$ vs. $35.6 \%, p=0.049)$ [4]. Thus, these studies have consistently indicated that adding postoperative chemotherapy and/or radiotherapy was able to improve OS among patients with $\mathrm{pN}+$ disease, relative to surgery alone $[3,4,6,8,16,25]$. However, no studies have directly attempted to determine whether $\mathrm{S}+\mathrm{CT}$ or $\mathrm{S}+\mathrm{CRT}$ is preferable in this setting, and the present study aimed to address this issue. The results from before and after the propensity score-matching indicate that $\mathrm{S}+\mathrm{CRT}$ provided better long-term OS and DFS, relative to $S+C T$.

Interestingly, Bedard et al. [21] have reported that S + CRT can cause biological changes in the tumor and reduce the possibility of subclinical or local recurrence. For patients underwent NCRT in CROSS study [11], the local regional recurrence have decrease significant (Anastomosis: $2.8 \%$ vs $8.7 \%, P=0.008$, Mediastinum: $7.0 \%$ vs $20.5 \%, \mathrm{P}<0.001)$. Only 9 patients have recurrence in RT field. The results showed that local radiotherapy plus surgery could significantly reduce the LRR, and the LRR in the irradiated field was even lower. The present study also revealed that $\mathrm{S}+\mathrm{CRT}$ was associated with a significantly lower LRR, especially for mediastinal recurrences, relative to $S+C T$. Thus, it is possible that ESCC may be sensitive to CRT, which might explain why $\mathrm{S}+$ CRT was more effective at improving the long-term OS and DFS outcomes. Furthermore, many studies have indicated that preoperative chemoradiotherapy significantly increases the $\mathrm{pCR}$, relative to preoperative chemotherapy [10-12, 22, 23]. Moreover, improvements in radiotherapy techniques have helped improve OS outcomes for locally advanced esophageal cancer, and 
improved surgical techniques have resulted in smaller postoperative radiotherapy targets $[9,24]$. Unfortunately, a radiation field limited to the mediastinal region is associated with a high supraclavicular and abdominal recurrence rate [13]. Thus, more precise treatments need to balance efficacy and treatment-related side effects, which suggest that further studies are needed to clarify the most appropriate chemotherapy regimens and radiation doses and target volumes.

The present study has several limitations. First, the retrospective data collection over a 10 -year period is prone to bias and confounding, although we attempted to minimize the effects by using propensity score matching to create two relatively comparable groups. For example, patients with KPS 90-100 can benefit from the $\mathrm{S}+\mathrm{CRT}$. Second, there have been various improvements in radiotherapy, chemotherapy, and surgical techniques during the 10-year period, which might have influenced our findings. Third, we only considered patients who were treated at a single institution. Fourth, the retrospective design precluded any analysis of patients who were not considered eligible for postoperative therapy because of their performance status.

In conclusion, we retrospectively evaluated patients with pN+ ESCC who underwent surgery followed by adjuvant chemotherapy or chemoradiotherapy. The results indicate that $\mathrm{S}+\mathrm{CRT}$ was associated with a substantial survival advantage in this setting. Therefore, further work is needed to better understand the role of adjuvant chemoradiotherapy for patients who have undergone esophagectomy for $\mathrm{pN}+\mathrm{ESCC}$.

\section{Supplementary information}

Supplementary information accompanies this paper at https://doi.org/10. 1186/s13014-020-01557-9.

\footnotetext{
Additional file 1. Supporting Table 1: univariate analysis of factors influencing overall survival and disease-free survival in the matched groups. Supporting Figure 1A-D: For patients with KPS scores of 90-100, the $S+C T$ and $S+C R T$ groups had similar 5 -year rates of OS and DFS. For patients with KPS scores of 70-80, the $S+$ CRT group had significantly better 5-year rates of OS (39.1\% vs. $17.8 \%, p=0.011)$ and DFS (31.9\% vs. $13.7 \%, p=0.038)$. DFS: disease-free survival; OS: overall survival; $\mathrm{S}+\mathrm{CT}$ : postoperative chemotherapy; S + CRT: postoperative chemoradiotherapy. Supporting Figure 2A-D: For patients with pT1-2 status, the $S+C T$ and $S+C R T$ groups had similar 5year rates of OS and DFS. For patients with pT3-4 status, the $S+C R T$ group had significantly better 5 -year rates of OS (39.6\% vs. $23.9 \%, p=0.043)$ and DFS (35.2\% vs. $23.2 \%, p=0.016)$. DFS: disease-free survival; OS: overall survival; S + CT: postoperative chemotherapy; S + CRT: postoperative chemoradiotherapy. Supporting Figure 3A-D: For patients with pN1 status, the S+ CT and S + CRT group had similar 5-year rates of OS and DFS. For patients with pN2-3 status, the $S+$ CRT group had significantly better 5 -year rates of OS (57.3\% vs. $36.4 \%, p=0.007)$ and DFS (52.1\% vs. $36.5 \%, p=0.007)$. DFS: disease-free survival; OS: overall survival; $\mathrm{S}+\mathrm{CT}$ : postoperative chemotherapy; S + CRT: postoperative chemoradiotherapy.
}

\section{Abbreviations}

ESCC: Esophageal Squamous Cell Carcinoma; $\mathrm{S}+\mathrm{CT}$ : Esophagectomy and adjuvant chemotherapy; S + CRT: Esophagectomy and adjuvant chemoradiotherapy; OS: Overall survival; DFS: Disease-free survival; NCRT: Neoadjuvant chemoradiotherapy; pN +: Pathologic lymph node metastasis.; LRR: Local-regional recurrence; HRs: Hazard ratios; Cls: Confidence intervals; S1: S1 stand for Gimeracil and Oteracil Porassium Capsules; MIE: Minimally invasive esophagectomy

\section{Acknowledgements}

This abstract have been selected for an Oral presentation in 2019 ASTRO annul meeting.

\section{Authors' contributions}

$\mathrm{QW}, \mathrm{YL}, \mathrm{LP}, \mathrm{YH}$, and TL conceived of the study, participated in its design, performed the statistical analysis, and helped draft the manuscript. YF, YW, $W L, X J$, and JY Lang participated in the design of the study. The authors read and approved the final manuscript.

\section{Funding}

This study was supported by a grant to develop "precision cloud radiotherapy" [2017YFC0113100], and the Sichuan Science and Technology Department key research and development project fund [2019YFS0378, 2018JY0277,2019YJ0581]. The funding sources played no role in the study's design, data analysis, or decision to publish the findings.

\section{Availability of data and materials}

The data supporting the findings of this study are available from the corresponding author upon reasonable request.

\section{Ethics approval and consent to participate}

The study's retrospective protocol was approved by the appropriate institutional review board.

\section{Consent for publication}

Not applicable.

\section{Competing interests}

Qifeng Wang, Jinyi Lang, Tao Li, Lin Peng, Wei Dai, Yinchun Jiang, Tianpeng Xie, Qiang Fang, Yi Wang, Lei Wu, Baorong Cao, and Yongtao Han declare that they have no competing financial interests.

\section{Author details}

'Department of Radiation Oncology,Sichuan Cancer Hospital \& Institution, Sichuan Cancer Center, University of Electronic Science and Technology of China, Radiation Oncology Key Laboratory of Sichuan Province, Chengdu 610041, China. ${ }^{2}$ Department of Medical Oncology,Sichuan Cancer Hospital \& Institution, Sichuan Cancer Center, University of Electronic Science and Technology of China, Radiation Oncology Key Laboratory of Sichuan Province, Chengdu 610041, China. ${ }^{3}$ Department of Thoracic Surgery, Sichuan Cancer Hospital \& Institution, Sichuan Cancer Center, School of Medicine, University of Electronic Science and Technology of China, Radiation Oncology Key Laboratory of Sichuan Province, Chengdu 610041, China.

Received: 3 April 2020 Accepted: 29 April 2020

Published online: 24 May 2020

References

1. Siegel RL, Miller KD, Jemal A. Cancer statistics, 2017. CA Cancer J Clin. 2017; 67:7-30.

2. Rice TW, Gress DM, Patil DT, et al. Cancer of the esophagus and esophagogastric junction-major changes in the American joint committee on cancer eighth edition cancer staging manual. CA Cancer J Clin. 2017;67: 304-17.

3. Zhang SS, Yang $H$, Xie $X$, et al. Adjuvant chemotherapy versus surgery alone for esophageal squamous cell carcinoma: a meta-analysis of randomized controlled trials and nonrandomized studies. Dis Esophagus. 2014;27:57484.

4. Rice TW, Ishwaran $\mathrm{H}$, Hofstetter WL, et al. Recommendations for pathologic staging (pTNM) of cancer of the esophagus and esophagogastric junction for the 8th edition AJCC/UICC staging manuals. Dis Esophagus. 2016;29: 897-905. 
5. Lee J, Lee KE, Im YH, et al. Adjuvant chemotherapy with 5-fluorouracil and cisplatin in lymph node-positive thoracic esophageal squamous cell carcinoma. Ann Thorac Surg. 2005;80:1170-5.

6. Chen J, Zhu J, Pan J, et al. Postoperative radiotherapy improved survival of poor prognostic squamous cell carcinoma esophagus. Ann Thorac Surg. 2010:90:435-42

7. Ando $\mathrm{N}$, lizuka $\mathrm{T}$, Ide $\mathrm{H}$, et al. Surgery plus chemotherapy compared with surgery alone for localized squamous cell carcinoma of the thoracic esophagus: a Japan clinical oncology group study--JCOG9204. J Clin Oncol. 2003;21:4592-6.

8. Xiao ZF, Yang ZY, Liang J, et al. Value of radiotherapy after radical surgery for esophageal carcinoma: a report of 495 patients. Ann Thorac Surg. 2003; 75:331-6.

9. Luketich JD, Pennathur A, Awais $\mathrm{O}$, et al. Outcomes after minimally invasive esophagectomy: review of over 1000 patients. Ann Surg. 2012;256:95-103.

10. Yang $\mathrm{H}$, Liu H, Chen Y, et al. Neoadjuvant Chemoradiotherapy followed by surgery versus surgery alone for locally advanced squamous cell carcinoma of the esophagus (NEOCRTEC5010): a phase III multicenter, randomized, open-label clinical trial. J Clin Oncol. 2018;36:2796-803.

11. van Hagen P, Hulshof MC, van Lanschot JJ, et al. Preoperative chemoradiotherapy for esophageal or junctional cancer. N Engl J Med. 2012:366:2074-84.

12. Samson P, Robinson C, Bradley J, et al. Neoadjuvant chemotherapy versus Chemoradiation prior to Esophagectomy: impact on rate of complete pathologic response and survival in esophageal cancer patients. J Thorac Oncol. 2016:11:2227-37.

13. Chen J, Pan J, Liu J, et al. Postoperative radiation therapy with or without concurrent chemotherapy for node-positive thoracic esophageal squamous cell carcinoma. Int J Radiat Oncol Biol Phys. 2013;86:671-7.

14. Wang Q, Yu S, Xiao Z, et al. Residual lymph node status is an independent prognostic factor in esophageal squamous cell carcinoma with pathologic T0 after preoperative radiotherapy. Radiat Oncol. 2015;10:142.

15. Leng $X$, He W, Yang $H$, et al. Prognostic impact of postoperative lymph node metastases after neoadjuvant Chemoradiotherapy for locally advanced squamous cell carcinoma of esophagus: from the results of NEOCRTEC5010, a randomized multicenter study. Ann Surg. 2019. https://doi.org/10.1097/ SLA.0000000000003727. [Epub ahead of print].

16. Takeuchi H, Miyata H, Ozawa S, et al. Comparison of short-term outcomes between open and minimally invasive Esophagectomy for esophageal cancer using a Nationwide database in Japan. Ann Surg Oncol. 2017;24: 1821-7.

17. Nakagawa S, Kanda T, Kosugi S, et al. Recurrence pattern of squamous cell carcinoma of the thoracic esophagus after extended radical esophagectomy with three-field lymphadenectomy. J Am Coll Surg. 2004; 198:205-11.

18. Khan TF. Long-term results of subtotal esophagectomy with three-field lymphadenectomy for carcinoma of the thoracic esophagus. Ann Surg. 1995;221:432.

19. Kato H, Tachimori $Y$, Watanabe $H$, et al. Recurrent esophageal carcinoma after esophagectomy with three-field lymph node dissection. J Surg Oncol. 1996;61:267-72

20. Mariette C, Balon JM, Piessen G, et al. Pattern of recurrence following complete resection of esophageal carcinoma and factors predictive of recurrent disease. Cancer. 2003;97:1616-23.

21. Bedard EL, Inculet Rl, Malthaner RA, et al. The role of surgery and postoperative chemoradiation therapy in patients with lymph node positive esophageal carcinoma. Cancer. 2001:91:2423-30.

22. Nakashima Y, Saeki H, Hu Q, et al. Neoadjuvant chemotherapy versus Chemoradiotherapy for patients with esophageal squamous cell carcinoma. Anticancer Res. 2018;38:6809-14.

23. Ando $\mathrm{N}$, Kato $\mathrm{H}$, Igaki $\mathrm{H}$, et al. A randomized trial comparing postoperative adjuvant chemotherapy with cisplatin and 5 -fluorouracil versus preoperative chemotherapy for localized advanced squamous cell carcinoma of the thoracic esophagus (JCOG9907). Ann Surg Oncol. 2012;19:68-74.

24. Dantoc MM, Cox MR, Eslick GD. Does minimally invasive esophagectomy (MIE) provide for comparable oncologic outcomes to open techniques? A systematic review. J Gastrointest Surg. 2012;16:486-94.

\section{Publisher's Note}

Springer Nature remains neutral with regard to jurisdictional claims in published maps and institutional affiliations.

Ready to submit your research? Choose BMC and benefit from:

- fast, convenient online submission

- thorough peer review by experienced researchers in your field

- rapid publication on acceptance

- support for research data, including large and complex data types

- gold Open Access which fosters wider collaboration and increased citations

- maximum visibility for your research: over $100 \mathrm{M}$ website views per year

At $\mathrm{BMC}$, research is always in progress.

Learn more biomedcentral.com/submissions 